\title{
D/H fractionation between water and the melts of quartz, K-feldspar, albite and anorthite at high temperature and pressure
}

\author{
Yoshimasu Kuroda, ${ }^{1}$ Yu Hariya, ${ }^{2}$ Tetsuro Suzuoki ${ }^{3}$ and Sadao Matsuo ${ }^{4}$ \\ Department of Geology, Sinshu University, Matsumoto, 390 Japan, ${ }^{1}$ \\ Department of Geology and Mineralogy, Hokkaido University, Sapporo, 060 Japan, ${ }^{2}$ \\ Marine Department, Japan Meteorological Agency, Otemachi, Tokyo, $100 \mathrm{Japan}^{3}{ }^{3}$ \\ and Department of Chemistry, Tokyo Institute of Technology, Meguro-ku, Tokyo, $152 \mathrm{Japan}^{4}$
}

(Received April 25, 1981: Accepted April 3, 1982)

\begin{abstract}
Quartz, K-feldspar, albite and anorthite were equilibrated with water vapor in Pt capsules at $20 \mathrm{~kb}$ and in the temperature range from 800 to $1,300^{\circ} \mathrm{C}$. The water in the capsules during the high temperature and pressure run seems to exist in two states, aqueous fluid and dissolved water (structural water) in the melt. In the process of extracting these waters, four kinds of water were distinguished experimentally: 1) Water extracted by puncturing the capsule in vacuum, 2) Water released from bubbles in quenched products, i.e., glasses, during grinding in an agate mortar 3 ) Water extracted from pulverized product in evacuation process at room temperature, and 4) Water extracted in vacuum at high temperature. $\mathrm{D} / \mathrm{H}$ ratios of waters of 1), 3) and 4) were measured. Taking water 4) to be dissolved water in melt, the fractionation factors between this and other waters from aqueous fluid were estimated. Deuterium is enriched in the dissolved water for albite and $\mathrm{K}$-feldspar melts, $\mathrm{D} / \mathrm{H}$ is almost the same for the aqueous fluid and dissolved water in the anorthite melt, and deuterium is much depleted in the dissolved water in the quartz melt.
\end{abstract}

\section{INTRDUCTION}

There is, in general, a miscibility gap between the dissolved water saturated in a granitic melt and the aqeuous fluid containing dissolved silicate material. For example, BURnHAm (1967) pointed out that the melt with $20 \mathrm{wt}$. $\%$ of water coexists with the aqueous fluid with $10 \mathrm{wt} . \%$ dissolved silicate material at the pressure equivalent to that of the base of the crust $(10 \mathrm{~kb})$. It is certain that there are two types of water, i.e., aqueous fluid and dissolved water when a magma is oversaturated with water.

The distinction in the properties of aqueous fluid and dissolved water has not yet been made clear. Dissolved water is considered to be in the silanol form of non-bridging terminal of $\mathrm{Si}_{\mathrm{n}} \mathrm{O}_{\mathrm{m}-1}(\mathrm{OH})_{2}$ according to, for example, BURNHAM (1979). Aqueous fluid, on the other hand, has been regarded as water vapor coexisting with magma, which retains colligative properties of water vapor, and aqueous fluid is present only when the magma is saturated with water.

Aqueous fluid and dissolved water are energetically different, and this difference should be reflected in $\mathrm{D} / \mathrm{H}$ fractionation between the two species.

When a magma is undersaturated with water, the most important and abundant species of water should be ordinary dissolved water. When a water-undersaturated magma intrudes into a certain level of the crust, the uptake of ambient water by the intruding magma and/or the change of dissolved water into aqueous fluid owing to the decrease in solubility of water in the magma may take place. As a result, two species of water, aqueous fluid and dissolved water, would occur after the magma becomes saturated with water.

In this study, we tried to estimate experimentally the $\mathrm{D} / \mathrm{H}$ fractionation between aqueous fluid and dissolved water in various silicate melts, with the intention to see if the fractionation is dependent on the composition of silicate melt. To start with, we used rock-forming min- 
erals such as quartz, K-feldspar, albite and anorthite as independent starting materials for the measurment of $\mathrm{D} / \mathrm{H}$ fractionation between aqueous fluid and dissolved water.

\section{EXPERIMENTAL}

Starting material Both crystalline and glassy materials were used for the experiments. A finely pulverized sample of a pure quartz crystal from Brazil supplied by Asahi Glass Co. was used as the starting material. A K-feldspar crystal was prepared by sintering a mixture of quartz, corundum and pottasium disilicate at $900^{\circ} \mathrm{C}$ for 7 days. An albite crystal was synthesized under hydrothermal condition of $750^{\circ} \mathrm{C}$ and $1 \mathrm{~kb}$ from homogeneous glass which was made by melting at $1,200^{\circ} \mathrm{C}$ a mixture of quartz, corundum and sodium disilicate. An anorthite crystal was synthesized at $800^{\circ} \mathrm{C}$ from a glass of anorthite composition made by melting a mixture of quartz, corundum and calcium carbonate at $1,600^{\circ} \mathrm{C}$.

Albite and anorthite glasses were also used as the starting materials.

The concentration and $\delta \mathrm{D}$ value of the water contained in these starting materials were analyzed by the procedures as will be described below and are presented in Table 1.

Starting water used is distilled tap water of Hokkaido University and its $\delta \mathrm{D}$ value was $-76 \%$.

High pressure technique A $10 \mathrm{~mm}$ long $\mathrm{Pt}$ tubing of $2.3 \mathrm{~mm}$ outer diameter and $0.15 \mathrm{~mm}$ wall thickness was sealed at one end. About $30 \mathrm{mg}$ of sample powder was packed into a capsule and weighed, and then about $10 \mathrm{mg}$ of water was added and weighed. The open end of the capsule was sealed while cooling the outside of the capsule to prevent vaporization of the water, and then weighed. The capsules without weight change before and after sealing were subjected to the runs.

High pressure experiments were carried out using a piston-cylinder apparatus. The pressure transmitting medium was sodium chloride with molten pyrex glass. The pressure cell was similar to that described by HARIYA and KENNEDY (1968). Reported pressures are believed to be accurate within $1 \mathrm{~kb}$. Temperature of the platinum capsules during the run was measured

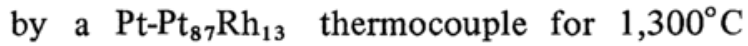
runs and by a chromel-alumel thermocouple for 800 and $1,000^{\circ} \mathrm{C}$ runs. No correction was made for the effect of pressure on emf of the thermocouples.

All the experiments were conducted under $20 \mathrm{~kb}$. The temperature was $1,300^{\circ} \mathrm{C}$ for quartz, anorthite and anorthite glass, $1,000^{\circ} \mathrm{C}$ for $\mathrm{K}$ feldspar, 800 and $1,000^{\circ} \mathrm{C}$ for albite and $800^{\circ} \mathrm{C}$ for albite glass. The period of run was five hours for quartz, anorthite and anorthite glass, five hours at $800^{\circ} \mathrm{C}$ for albite and albite glass, and three hours at $1,000^{\circ} \mathrm{C}$ for albite and two hours for K-feldspar. These periods of runs were long enough for establishing the isotopic equilibrium between dissolved water in melt and vapor. Níany repeated preliminary runs ranging from an hour to a week did not show any significant difference in the results. After each run, the capsule was cooled to about $100^{\circ} \mathrm{C}$ within about five seconds. Only the capsules without change in weight after runs were used for the present experiments.

In these experiments hydrogen gas may have been formed in capsules. In order to monitor the hydrogen diffusion through the Ptcapsule wall, capsules made from the same platinum tubing but containing only water were also treated under the same conditions. No measureable change in both amount and $\delta \mathrm{D}$

Table 1. Content and $\delta D$ of water contained in the starting materials

\begin{tabular}{lrrrccc}
\hline \hline & quartz & K-feld. & albite & anorth. & Ab-glass & An-glass \\
\hline $\mathrm{H}_{2} \mathrm{O}(\mathrm{wt} \%)$ & 0.16 & 0.31 & 1.64 & 0.23 & 0.19 & 1.40 \\
$\delta \mathrm{D}(\%)$ & -131 & -168 & -111 & -84 & -98 & -56 \\
\hline
\end{tabular}


Table 2. Results of extraction of water

\begin{tabular}{|c|c|c|c|c|c|c|c|c|c|c|c|}
\hline \multirow{2}{*}{$\mathrm{T}\left({ }^{\circ} \mathrm{C}\right)$} & \multicolumn{2}{|c|}{ quartz } & \multicolumn{2}{|c|}{ K-feldspar } & \multicolumn{3}{|c|}{ albite } & \multicolumn{2}{|c|}{ anorthite } & \multirow{2}{*}{$\begin{array}{c}\text { albite } \\
\text { glass } \\
800\end{array}$} & \multirow{2}{*}{$\begin{array}{c}\text { anorth. } \\
\text { glass } \\
1,300\end{array}$} \\
\hline & 1.300 & 1,300 & 1,000 & 1,000 & 1,000 & 1,000 & 800 & 1,300 & 1,300 & & \\
\hline $\mathrm{X}$ & 30.22 & 29.23 & 33.74 & 33.66 & 31.04 & 31.19 & 31.26 & 29.39 & 30.05 & 25.69 & 26.17 \\
\hline $\mathrm{X}^{*}$ & 30.20 & 29.21 & 33.64 & 33.55 & 30.53 & 30.62 & 30.75 & 29.32 & 29.98 & 25.64 & 25.80 \\
\hline $\mathbf{Y}$ & 10.73 & 11.01 & 10.60 & 10.95 & 10.62 & 10.50 & 9.71 & 9.53 & 9.95 & 10.89 & 10.99 \\
\hline $\mathrm{Y}^{*}$ & 10.75 & 11.03 & 10.70 & 11.06 & 11.13 & 11.01 & 10.22 & 9.60 & 10.02 & 10.94 & 11.36 \\
\hline A & 3.77 & 3.52 & 3.32 & 3.70 & 2.94 & 3.46 & 3.12 & 3.19 & 3.21 & 3.78 & 7.48 \\
\hline B & 3.76 & 3.21 & 3.00 & 3.13 & 2.43 & 3.35 & 3.03 & 3.25 & 3.08 & 2.97 & 5.69 \\
\hline $\mathrm{C}$ & 32.14 & 32.77 & 33.54 & 36.06 & 30.65 & 33.67 & 30.82 & 28.54 & 29.67 & 27.51 & 24.19 \\
\hline D & 25.80 & 27.01 & 29.72 & 31.04 & 26.85 & 30.57 & 28.34 & 25.89 & 26.50 & 23.70 & 16.90 \\
\hline E & 0.18 & 0.17 & 0.94 & 0.86 & 1.40 & 1.74 & 1.66 & 0.78 & 0.57 & 1.18 & 0.39 \\
\hline $\mathrm{F}$ & 1.42 & 1.92 & 1.66 & 1.84 & 2.35 & 2.65 & 2.42 & 3.05 & 3.45 & 1.97 & 2.23 \\
\hline G & 8.98 & 8.73 & 8.64 & 8.88 & 8.02 & 7.91 & 7.15 & 5.55 & 5.42 & 8.48 & 7.33 \\
\hline
\end{tabular}

Note: All numbers are presented in $\mathrm{mg}$.

$X$ : Starting material, $X^{*}: X-\left(\mathrm{H}_{2} \mathrm{O}\right.$ in $\left.X\right) ; Y$ : starting water, $Y^{*}: \mathrm{Y}^{*}\left(\mathrm{H}_{2} \mathrm{O}\right.$ in $\left.\mathrm{X}\right), \mathrm{A}$ : puncture loss, $\mathrm{B}$ : puncture water, $C$ : recovered sample after high $P-T$ run, $D$ : sample after grinding and the starting material for $E$ and $F, E$ : water extracted in vacuum at room temperature, $F$ : water extracted in vacuum at high temperatures, G: $Y^{*}-F\left[X^{*} /\{D-(E+F)\}\right]$.

value of this water was found before and after the runs. Therefore, we concluded that hydrogen penetration under the present experimental conditions was not significant to affect the experimental results.

Extraction of water A sealed platinum capsule after the high temperature and pressure run was punctured by a sharp tungsten needle in vacuum at room temperature. Free water in the capsule was extracted and was collected through a trap cooled by liquid nitrogen. In some cases a certain amount of hydrogen gas was recognized. It was converted into water by passing through heated $\mathrm{CuO}$ (about $500^{\circ} \mathrm{C}$ ). All the water thus obtained was transformed to hydrogen gas by heated uranium metal (about $700^{\circ} \mathrm{C}$ ) and the volume of evolved hydrogen gas was measured manometrically. This is called "puncture water" hereafter (B in Table 2).

The capsule was then taken out from the system and weighed. The difference of weight before and after puncturing is alloted to "puncture loss" (A in Table 2). The amounts of puncture water and puncture loss must be the same, but usually puncture loss was slightly larger than puncture water. The difference can be attributed to the loss of powder during puncturing in vacuum. Then the capsule was cut open with pliers, and the content was collected and weighed ( $\mathrm{C}$ in Table 2). This amount must be equal to $\mathrm{X}+\mathrm{Y}-\mathrm{A}$, where $\mathrm{X}$ and $\mathrm{Y}$ denote the weight of starting solid materials and water, respectively. Complete recovery of products from Pt-capsules after the runs, however, was extremely difficult, because the capsules were strongly deformed. A part of the products was left uncollected. Thus, $\mathrm{C}$ is always smaller than $\mathrm{X}+\mathrm{Y}-\mathrm{A}$.

In all the runs, the products were proved to be glassy. All the glasses contained a large number of bubbles as already described by many researchers, who conducted solubility experiments on similar glasses (BURNHAM and JAHNS 1962; BOETTCHER and WYLLIE 1969; ОХTOBY and Hamilton 1978; etc.). The glass was ground for a few minutes in an agate mortar in air. After grinding, the bubbles were not observable under the microscope and the weight decreased ( $D$ in Table 2). Therefore, $C-D$ should be equal to the weight of water in bubbles, if the bubbles consist of water and air as described later. However, C-D is larger than the weight of water in bubbles, since a part of products before grinding was used for the micro- 
Table 3. $\delta D$ value of water of different occurrences and the $D / H$ fractionation factor between dissolved water and aqueous fluid

\begin{tabular}{|c|c|c|c|c|c|c|c|c|c|c|c|}
\hline \multirow{2}{*}{$\mathrm{T}\left({ }^{\circ} \mathrm{C}\right)$} & \multicolumn{2}{|c|}{ quartz } & \multicolumn{2}{|c|}{ K-feldspar } & \multicolumn{3}{|c|}{ albite } & \multicolumn{2}{|c|}{ anorthite } & \multirow{2}{*}{$\begin{array}{c}\text { albite } \\
\text { glass } \\
800\end{array}$} & \multirow{2}{*}{$\begin{array}{c}\text { anorth. } \\
\text { glass } \\
1,300\end{array}$} \\
\hline & 1,300 & 1,300 & 1,000 & 1,000 & 1,000 & 1,000 & 800 & 1,300 & 1,300 & & \\
\hline $\mathrm{Y}^{*}$ & -76.1 & -76.1 & -76.9 & -76.9 & -77.8 & -77.8 & -78.0 & -76.1 & -76.1 & -76.1 & -75.4 \\
\hline B & -75.9 & -77.8 & -73.8 & -80.3 & -82.0 & -89.1 & -95.1 & -57.5 & -58.9 & -97.2 & -65.0 \\
\hline E & -89.1 & -87.4 & -96.9 & -94.2 & -94.4 & -99.9 & -101.8 & -86.7 & -95.8 & -75.2 & -85.6 \\
\hline $\mathbf{F}$ & -101.8 & -99.8 & -57.7 & -59.2 & -42.4 & -43.5 & -47.1 & -76.9 & -74.2 & -31.1 & -81.7 \\
\hline G & -71.0 & -69.9 & -81.5 & -81.2 & -91.5 & -91.2 & -91.3 & -75.5 & -77.7 & -89.2 & -71.9 \\
\hline$\alpha$ & 0.967 & 0.968 & 1.026 & 1.024 & 1.054 & 1.052 & 1.049 & 0.998 & 1.004 & 1.064 & 0.989 \\
\hline
\end{tabular}

Note: The notations are the same as those in Table 2. $\delta D$ values are presented in per mil, and $\alpha$ is that between dissolved water $(F)$ and aqueous fluid $(G)$, i.e., $\alpha=(D / H)_{F} /(D / H)_{G}$.

scopic observation in an immersion liquid. The ground sample was allowed to stand in a dry box for a period longer than 24 hours.

The sample was then placed into an extraction system and the system was pumped down at room temperature for an hour. In this process a certain amount of water was released $(E$ in Table 2). Finally the sample was completely dehydrated at about $1,400^{\circ} \mathrm{C}$ by induction heating in vacuum. The water obtained was transformed to hydrogen gas, and its amount $(\mathrm{F}$ in Table 2) and $\mathrm{D} / \mathrm{H}$ ratio were measured.

Mass-spectrometry The $\mathrm{D} / \mathrm{H}$ ratio of the hydrogen gas was measured by mass-spectrometers, Hitachi RMD and Varian-MAT 250, and the results are presented in Table 3 in SMOW scale. The overall error involved in $\delta \mathrm{D}$ measurement was $\pm 3 \%$.

\section{RESULTS AND DISCUSSION}

As many workers have already noticed, e.g., as seen in the microphotographs presented by BOETTCHER and WYLLIE (1969), quenched glasses of quartz or feldspar composition resulted from high temperature-pressure runs of $\mathrm{H}_{2} \mathrm{O}$-glass or $\mathrm{H}_{2} \mathrm{O}$-mineral systems contain many bubbles. We have tried to produce a glass without bubbles, but it has not yet been successful. Some interesting features of bubbles in glasses were found under the microscope. In a quartz glass, very small $(\sim 1 \mu \mathrm{m})$ and irregular shaped bubbles were seen. A K-feldspar glass contains small spherical bubbles $(3 \sim 4 \mu \mathrm{m})$ of two kinds: One is high relief, and the other is low and transparent. The former seems to be air bubbles and the latter to be water bubbles. In some part of the glass much smaller spherules $(\sim 1 \mu \mathrm{m})$ can be seen. When a glass contains a large amount of high relief bubbles, it looks like an opaque black mineral. In an albite glass there are also two kinds of bubbles similar to those in K-feldspar glass, but they are several times larger $(10 \sim 20 \mu \mathrm{m})$. An anorthite glass sometimes has lenticular bubbles of $20 \sim 30 \mu \mathrm{m}$ length consisting of two phases just like liquidgas inclusions, together with bubbles with a single phase. After a few minutes grinding in an agate mortar all the bubbles disappeared, but we could not collect the water in bubbles as mentioned already.

The difference in the shape and size distribution of bubbles among the glasses may be due to the difference in water content, viscosity and structure of the mineral melts before and during quenching.

We also carried out a series of experiments using albite and anorthite glasses as the starting materials through the same procedure and under the same condition. The results are included in Tables 2 and 3. In these cases also, bubbles were found but the shape and size were somewhat different. In both quenched glasses, bubbles have two sizes, i.e., $<1 \mu \mathrm{m}$ and around $10 \mu \mathrm{m}$. Both were spherules, and there were two kinds, viz. high relief one, and low relief and transparent one. 
As stated previously, we distinguished the following four kinds of water in the procedure of water extraction: 1) Water liberated in the process of puncturing Pt-capsules in vacuum (B in Table 2 and 3), 2) Water lost during grinding in an agate mortar (nearly equal to $\mathrm{C}-\mathrm{D}$ in Table 2), 3) Water extracted in evacuation process at room temperature ( $\mathrm{E}$ in Tables 2 and 3), and 4) Water extracted in vacuum at high temperatures ( $\mathrm{F}$ in Tables 2 and 3).

The sum of the amounts of the four kinds of water must be equal to the amount of the starting water, $\mathrm{Y}^{*}$ (refer to the footnote of Table 2 for notation). However, they do not agree precisely, mainly due to the difference between $\mathrm{X}+\mathrm{Y}-\mathrm{A}$ and $\mathrm{C}$, the amount of water actually recovered as mentioned in the previous section.

During the high pressure and temperature runs, at least two states of water seem to have existed in the capsules, aqueous fluid, and dissolved water (structural water in the form of silanol) in the melt. Aqueous fluid may be further divided into two categories: water vapor outside the melt and water vapor incorporated in the melt.

It is certain, however, that water extracted by puncturing the capsule in vacuum consists mainly of aqueous fluid outside the mineral melt. As for water in bubbles, we may assign it being derived from aqueous fluid incorporated in the melt during the quenching procedure. The water extracted at room temperature in vacuum (E) may be composed of aqueous fluid incorporated in the melt. The contribution from dissolved water to $\mathrm{E}$ may be very small, because the rate of decomposition of silanol seems to be quite slow at room temperature. On the other hand, water extracted at high temperatrues in vacuum (F) can be assigned exclusively to dissolved water.

As seen in Table 2, E/F is the highest for albite, and subsequent order of $\mathrm{E} / \mathrm{F}$ is $\mathrm{K}$-feldspar, anorthite and quartz. This difference may be a reflection of the difference in the ability of accomodating water vapor (incorporated aqueous fluid) in the melt. It is interesting to note that deuterium is consistently enriched in $\mathrm{F}$ as compared with E except for quartz as seen in Table 3.

We may define $\alpha,(\mathrm{D} / \mathrm{H})_{\text {dissolv }} /(\mathrm{D} / \mathrm{H})_{\text {aq.f1., }}$, in the following way on the basis of the discussion given above; dissolved water is allotted exclusively to water extracted at high temperature in vacuum (F), and all the other three kinds are originated from aqueous fluid (G), since the energetic difference between puncture water (B), water in bubbles, and water extracted at room temperature in vacuum (E) should be small. The amount of $\mathrm{G}$ can be calculated by material balance to be $\mathrm{G}=\mathrm{Y}^{*}-\mathrm{F}\left[\mathrm{X}^{*} /\{\mathrm{D}-(\mathrm{E}+\right.$ F) \} ]. (Refer to the footnote of Table 2 for notation) $\delta \mathrm{D}$ value of $\mathrm{G}$ in Table 3 was calculated using the following equation, $\mathrm{G} \cdot \delta \mathrm{D}_{\mathrm{G}}+$ $\left(\mathrm{Y}^{*}-\mathrm{G}\right) \cdot \delta \mathrm{D}_{\mathrm{F}}=\mathrm{Y}^{*} \cdot \delta \mathrm{D}_{\mathrm{Y}^{*}}$. Thus, $\alpha$ can be expressed as $(\mathrm{D} / \mathrm{H})_{\mathrm{F}} /(\mathrm{D} / \mathrm{H})_{\mathrm{G}}$. The calculated $\alpha$ is given in Table 3. The error attached to $\alpha$ is \pm 0.006 . The reproducibility of $\alpha$ for each melt is within the range of 0.006 .

As seen in Table $3, \alpha$ values of albite and $\mathrm{K}$-feldspar melts are definitely higher than unity. In other words, deuterium is certainly enriched in dissolved water and depleted in aqueous fluid in these cases. On the other hand, deuterium is definitely depleted in dissolved water in the case of quartz melt, and almost no fractionation occurs between anorthite melt and aqueous fluid.

If we assume that the temperature dependence of $\alpha$ and the dissolved water content, F/ (D-E), are not significant in the temperature range of this study (pressure was fixed at $20 \mathrm{~kb}$ ), the change in $\alpha$ and the content may be attributed to the change in chemical composition of the melt.

The content defined above was the highest for anorthite, albite second, and those of quartz and K-feldspar were the lowest. The order of contents, however, does not correlate with the trend of $\alpha$ for different melts.

The break-down of the linkage structure of $\mathrm{SiO}_{4}^{4-}$ due to the dissolution of water into the melt should have definite effect on $\mathrm{D} / \mathrm{H}$ fractionation between aqueous fluid and dissolved 
water. BURNHAM (1979) pointed out that when the water content of an albite melt is larger than $6.4 \%$, the mechanism of water dissolution can be considered to be, $\mathrm{Si}_{n} \mathrm{O}_{m}+\mathrm{H}_{2} \mathrm{O} \rightarrow$ $\mathrm{Si}_{\mathrm{n}} \mathrm{O}_{\mathrm{m}-1}(\mathrm{OH})_{2}$. If this mechanism holds for all the types of melts, some fraction of cations, if any, is made free on dissolution of water (for example, MYSEN and VIRGo 1980.)

As seen in Table 3, $\alpha$ of quartz melt, which has no cation to be liberated on water dissolution, is significantly smaller than unity. This fact can be interpreted if $\operatorname{Sin}_{n} \mathrm{O}_{m-1}(\mathrm{OH})_{2}$ is depleted in deuterium as compared with aqueous fluid. On the other hand, $\alpha$ of albite is definitely greater than unity, suggesting that the interaction of the liberated $\mathrm{Na}^{+}$and $\mathrm{Al}^{3+}$ with the non-bridging terminal of $\mathrm{Si}_{\mathrm{n}} \mathrm{O}_{\mathrm{m}-1}(\mathrm{OH})_{2}$ probably enhances deuterium enrichment in the latter. In the case of $\mathrm{K}$-feldspar $\mathrm{K}^{+}$and $\mathrm{Al}^{3+}$ react with $\mathrm{Si}_{\mathrm{n}} \mathrm{O}_{\mathrm{m}-1}(\mathrm{OH})_{2}$ to a lesser extent, and the interaction of $\mathrm{Ca}^{2+}$ and $\mathrm{Al}^{3+}$ with $\mathrm{Si}_{\mathrm{n}} \mathrm{O}_{\mathrm{m}-1}(\mathrm{OH})_{2}$ results in an equal distribution of deuterium between dissolved water and aqueous fluid in the case of anorthite.

When a melt of granitic composition (e.g., quartz $40 \%$, albite $30 \%$ and $\mathrm{K}$-feldspar 30\%) is taken into consideration, the dissolved water in the melt may be slightly enriched in deuterium as compared with the aqueous fluid if the additivity of isotopic fractionation holds. However, natural granites do not contain pure albite, but contain plagioclase. Our preliminary experiments on plagioclase melt with a variety of albite/anorthite composition showed that $\alpha$ is not linear with respect to albite/anorthite ratio, but is strongly affected by anorthite. The $\alpha$ of plagioclase with the composition, e.g., $\mathrm{Ab}_{70} \mathrm{An}_{30}$, should be much closer to that of pure anorthite, so that $\mathrm{D} / \mathrm{H}$ fractionation between dissolved water and aqueous fluid may be very slight for natural granitic melts.

Acknowledgment-A part of the expense of this study was defrayed by the Scientific Fund of the Ministry of Education, Science and Culture.

\section{REFERENCES}

BoetTCheR, A. L. and Wyllie, P. J. (1969) Phase relationship in the system $\mathrm{NaAlSiO}_{4}-\mathrm{SiO}_{2}-\mathrm{H}_{2} \mathrm{O}$ at 35 kilobar pressure. Am. J. Sci. 267, 875-909.

Burnham, C. W. (1967) Hydrothermal fluid at the magmatic stage. Geochemistry of hydrothermal ore deposits (ed. H. L. BARNES), New York, Holt, Rinehart and Wiston, 34-76.

BURNHAM, C. W. (1979) Magmas and hydrothermal fluid. Geochemistry of hydrothermal ore deposits, 2nd ed. (ed. H. L. BARNES), New York, Holt, Rinehart and Wiston, 71-135.

BURNHAM and JAHNS, R. H. (1962) A method for determining the solubility of water in silicate melts. Am. J. Sci. 260, 721-745.

HARIYA, Y. and KENNEDY, G. C. (1968) Equilibrium study of anorthite under high pressure and temperature. Am. J. Sci. 266, 193-203.

MYSEN, B. O. and VIRGO, D. (1980) Solubility mechanisms of water in basalt melt at high pressures and temperatures: $\mathrm{NaCaAl}-\mathrm{Si}_{2} \mathrm{O}_{7}-\mathrm{H}_{2} \mathrm{O}$ as a model, Am. Mineral. 65, 1176-1184.

OXTBY, S. and HAMILTON, D. L. (1978) The discrete association of water with $\mathrm{Na}_{2} \mathrm{O}$ and $\mathrm{SiO}_{4}$ in $\mathrm{NaAl}$ silicate melts. Contrib. Mineral. Petrol. 66, 185-188. 